\title{
Volumetric Analysis of the Prefrontal Cortex, Amygdala, and Hippocampus in Major Depression
}

\author{
Ramin S Hastings', Ramin V Parsey ${ }^{1,2}$, Maria A Oquendo ${ }^{1,2}$, Victoria Arango ${ }^{1,2}$ and J John Mann*,1,2 \\ 'Department of Neuroscience, New York State Psychiatric Institute, New York, NY, USA; ${ }^{2}$ Department of Psychiatry, Columbia University College \\ of Physicians and Surgeons, USA
}

\begin{abstract}
Magnetic resonance imaging (MRI) studies in depressed subjects report smaller volumes of amygdala, hippocampus, inferior anterior cingulate, and the orbital prefrontal cortex (OPFC), components of the limbic-cortico-thalamic circuit. Major depression occurs more commonly in women, raising the possibility of an additional psychopathological process affecting women and not men. We sought to determine whether volumetric differences related to mood disorders are dependent on sex. Eight male and 10 female depressed subjects, meeting DSM III R criteria for a major depressive episode, and eight male and I 0 female healthy volunteers had MRI scans on a I.5 T GE Signa Advantage scanner. The regions of interest included amygdala, hippocampus, inferior anterior cingulate, and OPFC. In all analyses, regional volumes were normalized for total cerebral volume. Volumetric changes in the ROls showed a significant sex by diagnosis interaction, indicating a different pattern of volumetric changes in depressed males compared with females relative to controls. Relative to sex-matched controls, the left inferior anterior cingulate was smaller in depressed males (23\%) compared with depressed females ( I 1\%). Depressed females but not depressed males had smaller amygdala compared with controls ( F-value $=4.946, p=0.033)$. No significant volumetric differences were noted in the hippocampus or OPFC. No volumetric correlations were noted with clinical variables, depression subtypes, or a reported history of sexual or physical abuse. Sex may affect volumetric deficits in amygdala and anterior cingulate cortex in mood disorders, but no effects were found in the hippocampus or OPFC. The biology of mood disorders in females may differ in some aspects from males, and may contribute to the higher rate of depression in women.

Neuropsychopharmacology (2004) 29, 952-959, advance online publication, 3 March 2004; doi: I 0. I038/sj.npp. I 30037 I
\end{abstract}

Keywords: amygdala; hippocampus; prefrontal cortex; volumetric; depression; subgenual; orbital

\section{INTRODUCTION}

Major depressive disorder (MDD) affects 13-14 million American adults each year (Kessler et al, 2003), with an annual prevalence of $12 \%$ in women compared with $7 \%$ for males (Nolen-Hoeksema, 1987). In addition, $21 \%$ of women will have an episode of major depression in their lifetime compared with $13 \%$ in males (Kessler et al, 1994). The higher prevalence of mood disorders in females raises the possibility of either more common stressors triggering episodes of depression, or sex differences in the diathesis and etiology leading to mood disorders (Kendler, 1998; Kendler et al, 2001; Khan et al, 2002). Although imaging studies of mood disorders have revealed a variety of differences in brain structure (Table 1), little is known about sex differences in the structural abnormalities associated with major depression.

*Correspondence: JJ Mann, New York State Psychiatric Institute, 1051 Riverside Drive, Box \# 42, New York, NY 10032, USA, Tel: + 1212 543 557I, Fax: + I 2125436017 , E-mail: jjm@columbia.edu Received 30 July 2003; revised 28 October 2003; accepted 21 November 2003

Online publication: 24 November 2003 at http://www.acnp.org/ citations/Npp I | 240303340/default.pdf
We reviewed the results of 17 magnetic resonance imaging (MRI) volumetric studies of mood disorders involving the amygdala, hippocampus, and the prefrontal cortex. Two early studies examined the hippocampusamygdala complex and found no difference in volume (Axelson et al, 1993; Coffey et al, 1993). Seven studies found a smaller hippocampus in depressed subjects compared with healthy volunteers (Bremner et al, 2000; Mervaala et al, 2000; Sheline et al, 1999, 1996; Steffens et al, 2000; Vythilingam et al, 2002), and two studies found no difference (Ashtari et al, 1999; Vakili et al, 2000). One study of depressed females found a smaller amygdala core (Sheline et al, 1998), and another study of males and females found a larger total amygdala volume in depressed subjects (Bremner et al, 2000). Studies involving the prefrontal cortex are more consistent, as four studies all found smaller volumes in the ventral prefrontal cortex, and anterior cingulate, although there is some disagreement about the precise regions involved (Botteron et al, 2002; Bremner et al, 2002; Drevets et al, 1997; Lai et al, 2000; Ongur et al, 1998). A post-mortem study by Ongur et al (1998) reported a smaller subgenual prefrontal cortex and loss of glial cells as a potential cause (Ongur et al, 1998; Rajkowska et al, 1999). 
Table I Studies of Volumetric Changes in Depressed Subjects (by Region and Year)

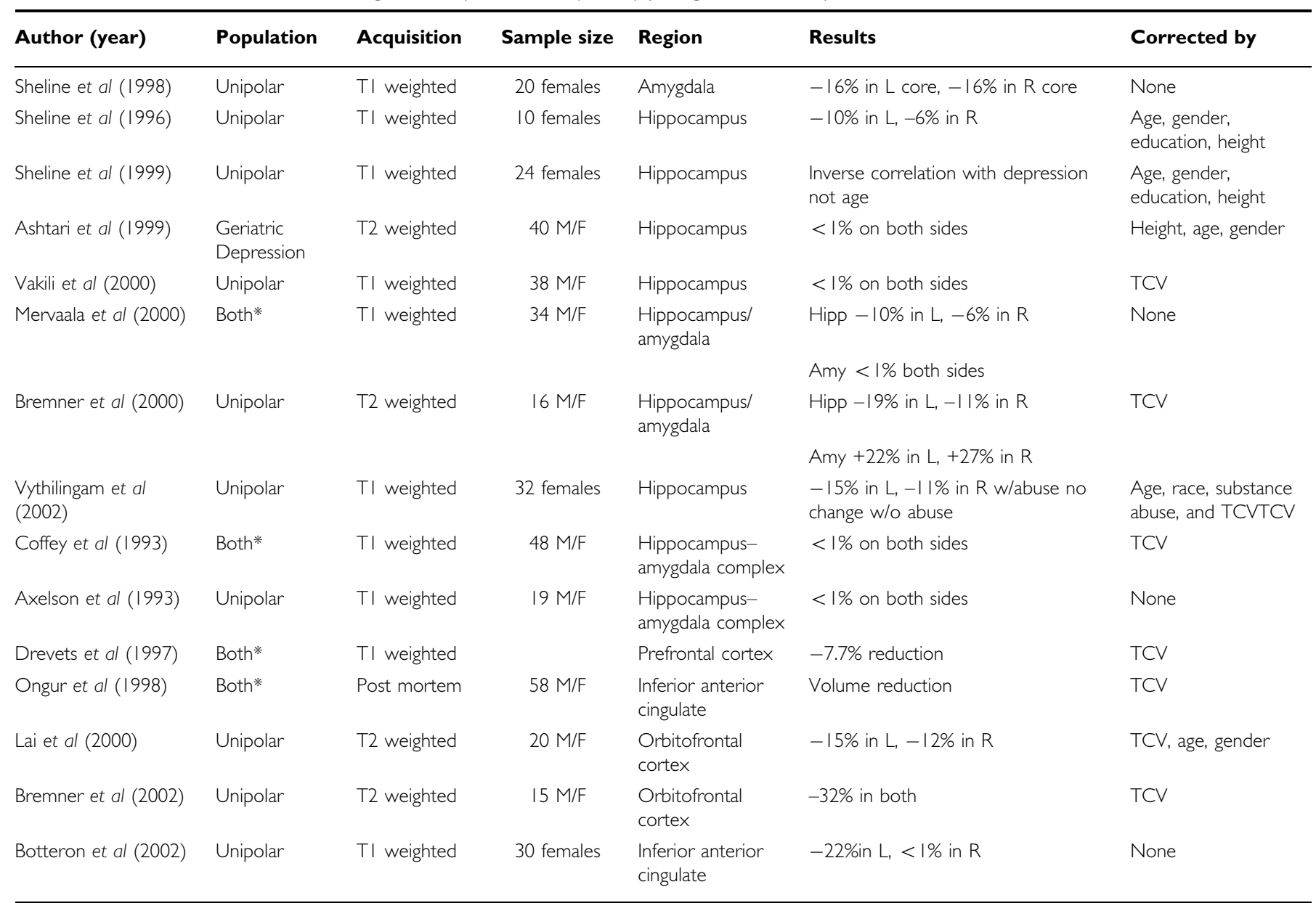

*Both $=$ unipolar and bipolar.

Of the 17 volumetric studies in depression, only two examined differences based on sex. Vakili et al (2000) reported that depressed females showed a trend toward a smaller normalized volume of the left hippocampus compared with male depressed subjects. Steffens et al (2000) also found smaller hippocampal volume in depressed or healthy females, compared with depressed or healthy males. Some volumetric studies examined regional volumes in females only (Botteron et al, 2002; Sheline et al, 1998, 1999, 1996; Vythilingam et al, 2002). All of these studies found smaller hippocampal volumes in female depressed subjects when compared with female healthy controls. In contrast, only half of the studies that examined both males and females found smaller volumes in the hippocampus (Bremner et al, 2000; Mervaala et al, 2000). This is evidence that sex influences the volumetric changes in the hippocampus in depression. In addition, our group conducted positron emission tomography (PET) receptor-binding studies of the serotonin $5-\mathrm{HT}_{1 \mathrm{~A}}$ receptor in the prefrontal cortex, amygdala, and hippocampus. Our results showed higher binding potential in healthy females when compared with healthy males (Parsey et al, 2002). This evidence suggests the possibility of a sex effect on the volume of brain regions in mood disorders.
The goals of this study were to investigate the effect of sex on putative volumetric changes in the amygdala, hippocampus, inferior anterior cingulate, and orbital prefrontal cortex (OPFC) in depressed subjects compared to healthy volunteers, and to explore the effects of clinical variables (number of major depressive episodes, age at first major depressive episode, age, reported history of abuse, and years of education) on the volume of these brain regions.

\section{MATERIALS AND METHODS}

\section{Subjects}

Eight male and 10 female subjects, recruited from community referrals and advertisements, were diagnosed with MDD based on the Structured Clinical Interview DSM-III-R (Spitzer et al, 1992) patient version (SCID-P). Depressed subjects were free of medical illness and drugs based on history, physical examination, and laboratory tests, including liver function tests, hematological profile, thyroid function tests, urinalysis, and drug toxicology. Eight male and 10 female healthy volunteers did not have any Axis I diagnosis based on the SCID-NP (nonpatient version) and were free of medical illness and drugs as assessed above. Pregnant females were excluded. All subjects entered the 
study after giving written informed consent as approved by the Columbia University and New York State Psychiatric Institute Institutional Review Boards. Basic demographic information, past psychiatric and treatment history, family history, and developmental history were acquired using the Columbia Baseline Demographic Form. This form also systematically asks about physical and sexual abuse in childhood (before the age of 15 years). One subject who was subsequently found to be on medication at the time of the MRI scan was excluded, as were seven subjects with diagnosed bipolar disorder.

\section{MRI Acquisition and Analysis}

MRI scans were acquired on a 1.5 T GE Signa Advantage scanner (GE Medical Systems, Waukesha, WI) with a T1weighted axial MRI sequence, slices parallel to the AC-PC line (three-dimensional SPGR or spoiled gradient recalled acquisition), producing thin-section images of the whole brain, with gradient-echo parameters of TR $34 \mathrm{~ms}$, TE $5 \mathrm{~ms}$, flip angle of $45^{\circ}$. Slice thickness was $1.5 \mathrm{~mm}$, zero gap, 124 slices, FOV $22 \times 16 \mathrm{~cm}^{2}$, with $256 \times 192$ matrix, reformatted to $256 \times 256$, giving $1.5 \times 0.78 \times 0.78 \mathrm{~mm}^{3}$ voxels. MRI images were analyzed on a Sun Ultra 5 computer system (Sun Microsystems Ultra 5, Palo Alto, CA), utilizing the MEDX image analysis program (Sensor Systems Inc., Sterling, VA). All of the regions of interest (ROIs) were drawn by one rater ( $\mathrm{RSH})$ in the axial view with threedimensional contours created and verified by a neuroanatomist (VA). Total cerebral volume (TCV) was defined as the volume of the entire right and left hemispheres of the brain, the cerebellum, and brainstem extending to the inferior boundary of the cerebellum. TCV was computed using a segmentation script used along with the MEDX software. All ROIs were normalized by dividing the ROI volume into $\mathrm{mm}^{3}$ by the TCV in liters to obtain normalized volume units of $\mathrm{mm}^{3} / \mathrm{L}$.

\section{Amygdala-Hippocampus Volume Determination}

Figure 1 shows the ROIs in the axial and sagittal views. Many recent methods have been used to determine amygdala volume (Achten et al, 1998; Aylward et al, 1999; Bernasconi et al, 1999; Convit et al, 1999). We chose the published guidelines used by Sheline et al (1996) to obtain comparable results to previous depression volumetric studies of the amygdala (Bartzokis et al, 1993). The amygdala is defined as the gray matter beginning posterior to the coronal slice containing the decussation of the anterior commissure. A line perpendicular to the midline is drawn on each axial slice corresponding to this coronal slice. Laterally, the region includes all gray matter between the cerebral peduncle and the inferior horn of the lateral ventricle. Axial slices superior to the parahippocampal gyrus were used to draw the amygdala and the hippocampus. The superior boundary of the hippocampus corresponds to higher axial slices as the hippocampus extends posteriorly. The temporal horn marks the inferiorlateral boundary of the amygdala and the anterior end of the hippocampus, while the atrium of the lateral ventricle marks the superior boundary at the posterior end of the hippocampus. A thin line of white matter, the alveus,
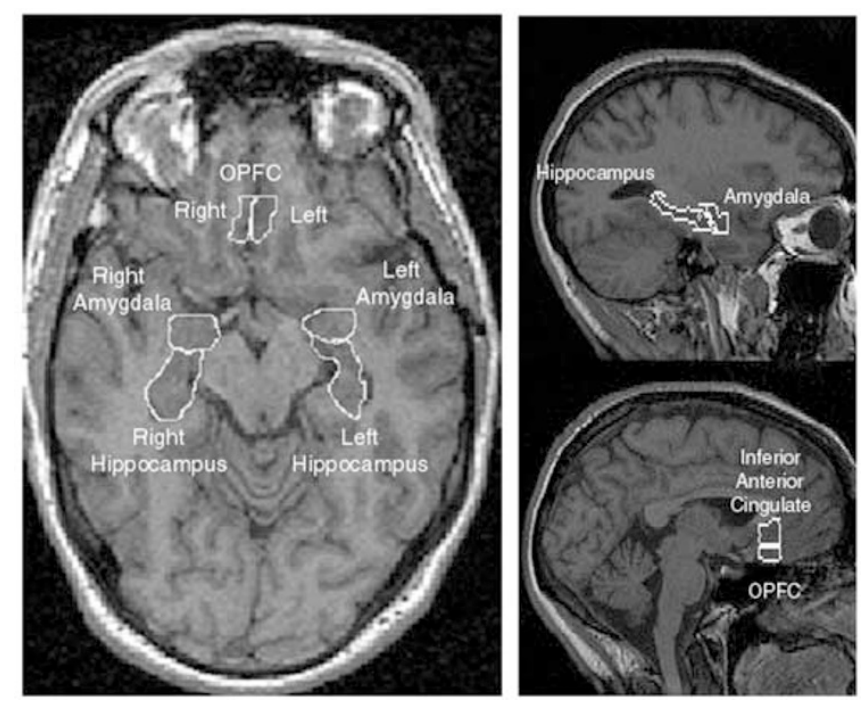

Figure I Illustration of methods used to determine ROls. Axial view of the amygdala, hippocampus, and OPFC (left panel); the sagittal view of amygdala and hippocampus (upper right panel); sagittal view of OPFC and inferior anterior cingulate (lower right panel). Regions were drawn on axial slices using the sagittal views as guides.

separates the amygdala and hippocampus, on each axial slice. However, in the more superior axial slices, the amygdala and hippocampus are completely separated. The amygdala and hippocampus were drawn on both the left and right hemispheres. The intrarater reliability of the regions was computed by repeated measurements, and the inner class coefficient (ICC) for the amygdala was 0.99 on the left side and 0.91 on the right side. The ICC for the hippocampus was 0.89 on the left side and 0.88 on the right side. These ICC values are consistent with previous studies of the amygdala and hippocampus (Sheline et al, 1998, 1999).

\section{Inferior Anterior Cingulate Cortex and OPFC Volume Determination}

The cortex inferior to the genu of the corpus callosum is separated into the inferior anterior cingulate and the OPFC, which were drawn in axial slices between the inferior aspect of the brain and the inferior side of the genu of the corpus callosum. The anterior and posterior boundaries consist of the gray matter between perpendiculars dropped from the anterior and posterior surfaces of the genu of the corpus callosum. Perpendicular lines are drawn on the axial slices that corresponded to these borders. The inferior boundary of the inferior anterior cingulate cortex is the cingulate sulcus, which is also the superior boundary of the OPFC, and this boundary is determined in the sagittal view. The gray matter extends laterally from the medial aspect of the left and right hemispheres. The region we refer to here as the inferior anterior cingulate is called the subgenual prefrontal cortex by Drevets et al (1997). The intrarater reliability ICC value for the inferior cingulate is 0.77 on the left side and 0.60 on the right side. The ICC for the OPFC is 0.80 on the left side and 0.70 on the right side. These values 
are consistent with previous studies of the prefrontal cortex (Bremner et al, 2002).

\section{Statistical Analysis}

$\chi^{2}$ tests were used to compare dichotomous demographic variables between the depressed subjects and healthy volunteers. Group comparisons of volumetric differences in the ROIs were performed using a two-tailed Student's $t$ test and a repeated measures analysis of variance (ANOVA) with the left and right side of the ROI as the repeated measure. These analyses were performed with StatView (SAS Institute Cary, NC), with statistical significance defined as $p<0.05$. Pearson correlations were estimated between the brain region volumes and clinical variables for the group as a whole, and separately by diagnosis. Simple regression analyses were estimated with all of the normalized ROI volumes and the various clinical variables. $R^{2}$ values and $p$-values were noted for each regression and a $p<0.05$ was considered significant.

\section{RESULTS}

\section{Subject Demographics}

As seen in Table 2, the healthy volunteers and the depressed subjects did not differ in age, sex, or handedness. Healthy volunteers had two more years of education compared to the depressed subjects. The depressed subjects consisted of 12 inpatients and 6 outpatients, and had between 1 and 20 lifetime major depressive episodes, with a mean of $4.7 \pm 4.4$. The average age at first major depressive episode was

Table 2 Demographics of the Depressed Subjects and Healthy Volunteers

\begin{tabular}{|c|c|c|c|c|c|}
\hline \multirow[b]{2}{*}{ Characteristic } & \multirow{2}{*}{$\begin{array}{c}\text { Depressed } \\
(N=18) \\
N\end{array}$} & \multirow{2}{*}{$\begin{array}{c}\text { Healthy } \\
\text { volunteers } \\
(\mathbf{N}=18) \\
N\end{array}$} & \multicolumn{3}{|c|}{ Analysis } \\
\hline & & & df & $\chi^{2}$ & $p$ \\
\hline Sex & & & I & 0.000 & 1.00 \\
\hline Male & 8 & 8 & & & \\
\hline Female & 10 & 10 & & & \\
\hline Handedness & & & I & 0.000 & 1.00 \\
\hline Right & 16 & 16 & & & \\
\hline \multirow[t]{2}{*}{ Left } & 2 & 2 & & & \\
\hline & Mean & Mean & & Student's $t$ & $p$ \\
\hline Age (years) & $38.9 \pm 11.4$ & $34.8 \pm 13.6$ & 34 & 0.986 & 0.331 \\
\hline $\begin{array}{l}\text { Total education } \\
\text { (years) }\end{array}$ & $16.4 \pm 2.8$ & $18.3 \pm 3.3$ & 34 & 1.865 & 0.071 \\
\hline $\begin{array}{l}\text { Age of onset of } \\
\text { MDE (years) }\end{array}$ & $23 \pm 12.3$ & N/A & & & \\
\hline $\begin{array}{l}\text { Number of } \\
\text { major depressive } \\
\text { episodes }\end{array}$ & $4.7 \pm 4.4$ & 0 & & & \\
\hline
\end{tabular}

$23 \pm 12.3$ years (range: $8-35$ years). Nine depressed subjects had previously attempted suicide, and two were diagnosed with post-traumatic stress disorder. Four subjects experienced physical abuse and two subjects experienced sexual abuse before the age of 15 years.

\section{Total Cerebral Volume}

Healthy volunteers and depressed subjects showed no detectable differences in TCV $(1.40 \pm 0.27 \mathrm{~L} v s 1.43 \pm 0.14 \mathrm{~L}$ respectively, $t=0.434, \mathrm{df}=34, p=0.664)$. TCV was not detectably different between males and females (1.44 \pm $0.17 \mathrm{~L} \quad v s \quad 1.40 \pm 0.25 \mathrm{~L}$ respectively, $t=0.522, \quad \mathrm{df}=34$, $p=0.589$ ). All ROI volumes are normalized by TCV.

\section{Volumetric Changes by Group and Sex}

In the healthy volunteer population, the normalized region volumes for all ROIs were not different between males and females (data not shown). A repeated measures ANOVA of each ROI with diagnosis and sex as independent variables showed that there is a sex by diagnosis interaction effect only in the amygdala $(\mathrm{F}=4.946, \mathrm{df}=1,32, p=0.033)$, with no diagnosis effect (Figure 2). Compared with healthy female volunteers, female depressed subjects had a $23 \%$ smaller right amygdala (see Figure 3) $(1845 \pm 225$ vs $1411 \pm 253, t=4.050, \mathrm{df}=18, p<0.001)$, and showed a trend toward $15 \%$ smaller left amygdala volume $(1718 \pm 339$ vs $1454 \pm 307, t=1.831, \mathrm{df}=18, p=0.084)$. Depressed males

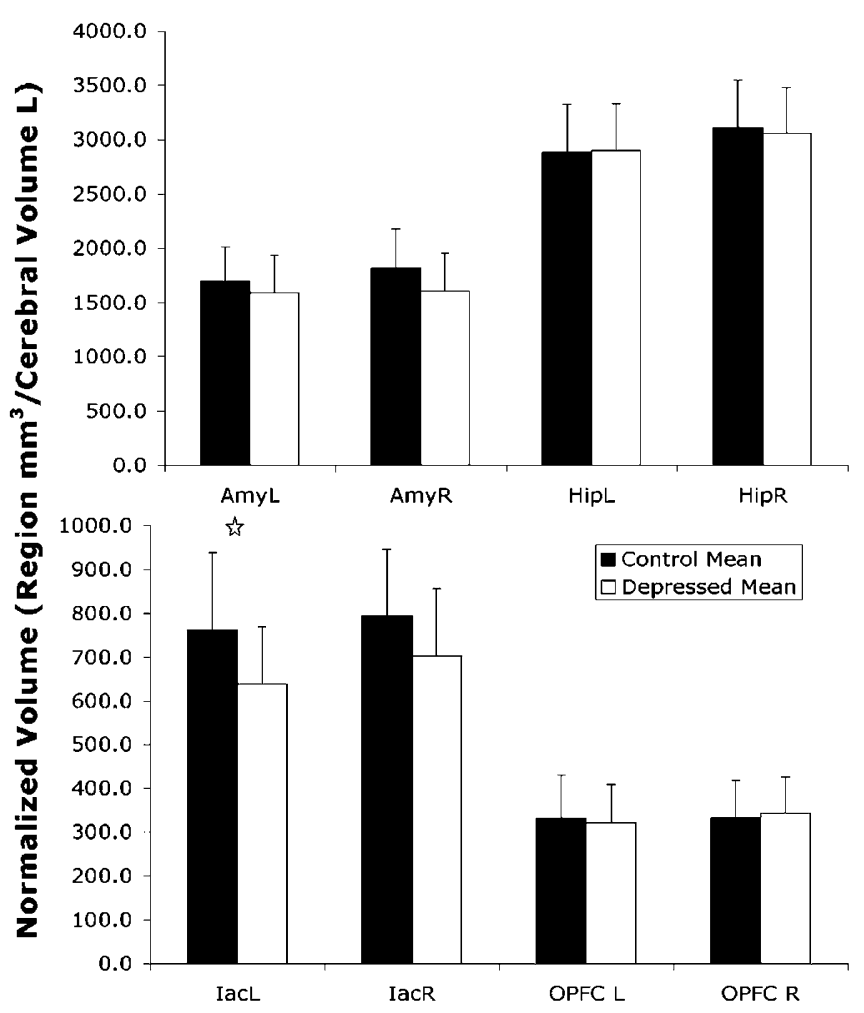

Figure 2 Normalized regional volumes. A trend for lower volumes in the depressed subjects is noted in every region, except the left hippocampus. The right amygdala (AmyR) and the left inferior anterior cingulate (lacL) are significantly lower than in healthy volunteers $* 0<0.05$ (Hip = hippocampus, OPFC $=$ orbital prefrontal cortex). 


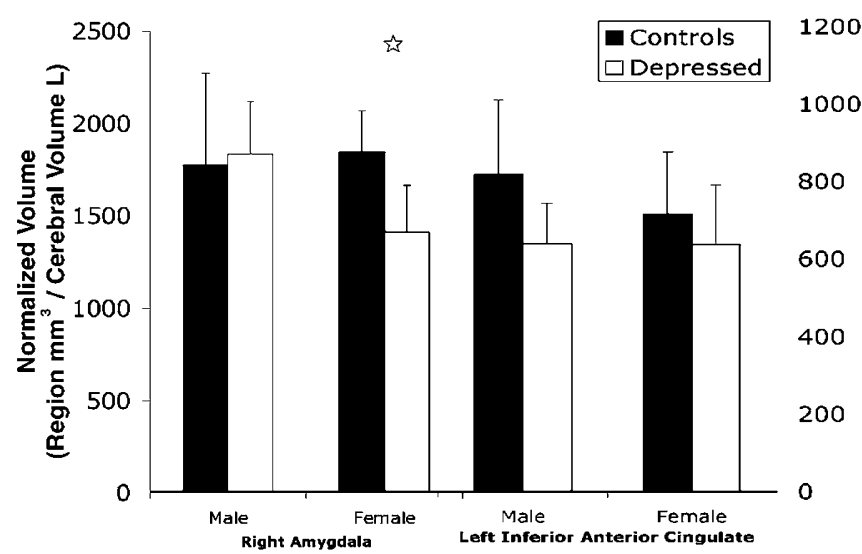

Figure 3 Normalized region volumes segregated by sex. Female depressed subjects had lower volumes than female healthy volunteers in the right amygdala (mean diff. $=-433.5, \mathrm{df}=18, \quad p=0.00 \mathrm{I}$ ). Male depressed subjects had lower volumes than male healthy volunteers in the left inferior anterior cingulate (mean difference $=-157.2, \mathrm{df}=15$, $p=0.057) . *{ }^{*} p<0.05$.

had no difference in amygdalar volume compared to healthy males (Figure 3). Repeated measures ANOVA of the inferior anterior cingulate volume showed a significant diagnosis effect $(\mathrm{F}=4.567, \mathrm{df}=1.34, p=0.039)$ (Figure 2), and no sex effect. Post hoc analysis confirmed that male depressed subjects had a $22 \%$ smaller left inferior anterior cingulate normalized volume when compared with male healthy volunteers $\quad(817 \pm 193$ vs $639 \pm 105, \quad t=2.291, \quad \mathrm{df}=14$ $p=0.038)$. When compared with female healthy volunteers, depressed female subjects had no difference in left inferior anterior cingulate normalized volume $(715 \pm 160$ vs $636 \pm 156, t=1.129, \mathrm{df}=18, p=0.274)$. The right inferior anterior cingulate did not differ between healthy patients and depressed subjects in either males $(827 \pm 150$ vs $729 \pm 104, \quad t=1.528, \quad \mathrm{df}=14, \quad p=0.149) \quad$ or females $(769 \pm 158$ vs $680 \pm 188, t=1.141, \mathrm{df}=18, p=0.269)$. The left and right OPFC and hippocampi did not differ from healthy volunteers in male or female depressed subjects (data not shown).

\section{Correlations with Clinical and Demographic Variables}

No significant correlations were observed between normalized volume determinations in the ROIs and clinical variables including age, total years of education, age at first episode of major depression, and number of major depressive episodes (data not shown). No differences were detected in the normalized volume determinations within the depressed population when grouped by family history of depression, reported history of sexual or physical abuse, or suicide attempt status (data not shown).

\section{DISCUSSION}

We found a different pattern of regional volumetric changes in male depressed subjects relative to healthy males, compared to female depressed subjects relative to healthy females. A smaller amygdala is present only in depressed females. In contrast, a smaller normalized left inferior anterior cingulate was found in depressed males but not females. Our sample of depressed subjects did not exhibit detectible volumetric differences in the hippocampus or OPFC. No effects of age of depression onset, number of major depressive episodes, depression subtype, reported abuse, or education was found.

Smaller amygdala volume is noted in depressed subjects, when compared to healthy controls. Only depressed females show smaller volume in the amygdala, and the repeated measures ANOVA shows a sex by diagnosis interaction effect in the amygdala. Volumetric differences of the amygdala have not been consistently found in major depression, with studies reporting smaller core amygdala volume (Sheline et al, 1998), or larger total amygdala volume in depression (Bremner et al, 2002). Smaller amygdala volume is consistent with post-mortem studies of the amygdala, reporting fewer glial cells in major depression (Bowley et al, 2002). Sheline et al (1998) studied only females, and like our study, she found that depressed females have smaller amygdala volume.

Lesions involving the amygdala change emotional responses, including inability to recognize facial expressions (Adolphs et al, 1994). Electrical stimulation of the amygdala evokes strong emotions, including recalling emotional events (Sarter and Markowitsch, 1985). The amygdala manifests increased activity after subjects are exposed to sad facial expressions (Adolphs et al, 1999), and has greater activity in depressed subjects (Drevets, 1999).

Abuse experiences are reported more commonly by females and may affect the amygdala (Penza et al, 2003). In addition, enhanced dendritic arborization has been noted in rats under chronic immobilization stress (Vyas et al, 2002). We found no relationship between amygdala volume and reported abuse history, but our subject sample size is too small to draw firm conclusions. More research is needed to understand fully the sex differences in stress and depression, and the pathophysiology of female amygdala volumetric differences in depression.

In the prefrontal cortex, we found smaller left inferior anterior cingulate volume in males but not in females. Four previous studies concurred that the parts of the frontal lobe are smaller in major depression, although agreement is lacking on the precise subregions (see Table 1). Drevets et al (1997) found a smaller volume in a region defined as the subgenual prefrontal cortex, which we call inferior anterior cingulate. Botteron et al (2002) report similar results.

Reports of altered activity in the anterior cingulate (Drevets, 1999; Kegeles et al, 2003; Mayberg et al, 1999) in depression and changes with treatment may reflect statedependent effects on function. Effects of treatment on structure remain to be further evaluated. The prefrontal cortex plays a role in mood and visceral regulation (Fuster, 1997), and damage to the prefrontal cortex results in problems in mood, emotion, impulse control, and social dysregulation (Bremner et al, 2002; Morgan et al, 1993). Bremner et al (2002) showed an increase of depressive symptoms and decreased orbitofrontal cortical metabolism with tryptophan depletion, which may be the result of less serotonin activity. Mayberg et al (1999) has shown that depressed mood induction in healthy volunteers alters prefrontal cortical activity, and that successful treatment 
returns prefrontal cortical activity towards normal. Some hypothesize that the smaller volume in the prefrontal cortex may be related to fewer glial cells (Ongur et al, 1998; Rajkowska et al, 1999). However, the mechanism underlying this volume change is unknown, and requires further quantitative morphometric studies to rule out neuronal changes.

We found no difference in hippocampal volume when comparing depressed subjects to healthy controls, in either males or females. The hippocampus has been implicated in mood regulation and even more so in memory (Aggleton, 2000; Damasio et al, 1985; Gray, 1983; Seifert, 1983; ZolaMorgan and Squire, 1990). Volumetric changes in the hippocampus, in depressed subjects, have not been consistently replicated (Table 1). Only two studies, Vakili et al (2000) and Bremner et al (2000), have used TCV normalized ROIs. The former study had more than twice the number of subjects than the latter, and in agreement with our study, did not detect a significant difference between depressed subjects and healthy volunteers. However, the inconsistent findings may also be accounted for by differences in subject populations or anatomical definition and identification of the brain structures. Some studies have concentrated on older patients (Ashtari et al, 1999; Sheline et al, 1996; Steffens et al, 2000), whereas our study focused on young and middle-aged patients. Sheline et al (1996) found a smaller volume in the hippocampus in female depressed subjects with an average age of 68 years, while our sample had an average age of 39 years. In addition, Sheline's subjects were taking antidepressants, whereas our subjects were medication free at the time of the scan. A possible explanation of these conflicting results is that a reduction in the hippocampal volume may only occur after sustained periods of depression, and presents later in life (Sheline et al, 1999). Some hypothesize that chronically elevated levels of glucocorticoids, found in major depression (Sapolsky, 2000), play a role in hippocampal atrophy.

Women with MDD who have suffered childhood trauma reportedly have smaller hippocampal volume (Vythilingam et al, 2002). We found no difference between females who suffered childhood trauma from those who did not; however, our sample of patients with a history of abuse was small $(N=5)$, limiting statistical power.

A larger sample size may extend our findings. A power analysis assuming a power of 0.80 , and a $95 \%$ confidence level suggests that a sample size of 25 females would be needed to gain a significant difference, with our measured standard deviation and 15\% difference in right amygdala normalized volume. In addition, the right inferior anterior cingulate, with our measured standard deviation and $12 \%$ mean normalized volume difference, requires a sample size of 44 to demonstrate significance between depressed subjects and healthy controls, including males and females. Although our sample size is small for studying gender differences, the results are striking. However, replication in a future study with a larger sample size is required.

Historically, in order to account for confounding variables such as intelligence, education, age, etc, investigators have either included these variables in their statistical analysis or normalized the ROI volume to the total brain volume. We chose the latter approach because it parsimoniously accounted for variables such as sex, years of education, age, height, and TCV (data not shown). For example, even though our sample of depressed subjects had fewer years of education than the healthy volunteers, we believe that our normalization technique accounts for differences in the level of education. In both the healthy volunteers and the depressed subjects, no regression $p$ values of less than 0.2 were noted using the confounding variables age, sex, and total education, when the volumes are normalized to TCV. When the region volumes are not normalized to TCV, there are significant correlations. This change in regression values shows the power of the normalization technique. No difference is noted in TCV between depressed subjects and control subjects, suggesting that the use of TCV in our normalization technique can reduce the 'noise' due to these confounding variables, and increase the statistical power of the analyses for our major hypotheses.

A small amount of white matter is included within the ROIs. The method of manual tracing is the most common method for analyzing volumetric differences in ROIs. Although attempts have been made to segment the gray matter of such ROIs (Ashton et al, 1995), the results are unreliable and have not been used in this or previous volumetric studies.

Our study demonstrates that the pattern of brain structural changes associated with major depression is different in males and females. These sex differences in brain regional volumes in depression may be associated with differences in pathobiology and have implications for treatment and outcome (Kuehner, 2003; Sloan and Kornstein, 2003), and may explain the higher prevalence of mood disorders in women. However, only two previous volumetric studies of the amygdala, hippocampus, inferior cingulate, or the SGPFC examined gender differences (Steffens et al, 2000; Vakili et al, 2000). The gender-based differences found in this study are preliminary and require further volumetric studies with larger sample sizes to confirm the results. A voxel-based morphometric study examining gender differences in depression will also be helpful in identifying volumetric gender-dependent differences throughout the brain.

\section{ACKNOWLEDGEMENTS}

This work was supported by US PHS grants NIMH P30 MH46745, MH40695, NIMH K02-MH01603, and NARSAD.

\section{REFERENCES}

Achten E, Deblaere K, De Wagter C, Van Damme F, Boon P, De Reuck J et al (1998). Intra- and interobserver variability of MRIbased volume measurements of the hippocampus and amygdala using the manual ray-tracing method. Neuroradiology 40: 558-566.

Adolphs R, Tranel D, Damasio H, Damasio A (1994). Impaired recognition of emotion in facial expressions following bilateral damage to the human amygdala. Nature 372: 669-672.

Adolphs R, Tranel D, Hamann S, Young AW, Calder AJ, Phelps EA et al (1999). Recognition of facial emotion in nine individuals with bilateral amygdala damage. Neuropsychologia 37: 1111-1117. 
Aggleton JP (2000). The Amygdala: A Functional Analysis, 2nd edn Oxford University Press: Oxford, New York.

Ashtari M, Greenwald BS, Kramer-Ginsberg E, Hu J, Wu H, Patel $\mathrm{M}$ et al (1999). Hippocampal/amygdala volumes in geriatric depression. Psychol Med 29: 629-638.

Ashton EA, Berg MJ, Parker KJ, Weisberg J, Chen CW, Ketonen L (1995). Segmentation and feature extraction techniques, with applications to MRI head studies. Magn Reson Med 33: 670-677.

Axelson DA, Doraiswamy PM, McDonald WM, Boyko OB, Tupler LA, Patterson LJ et al (1993). Hypercortisolemia and hippocampal changes in depression. Psychiatry Res 47: 163-173.

Aylward EH, Minshew NJ, Goldstein G, Honeycutt NA, Augustine AM, Yates KO et al (1999). MRI volumes of amygdala and hippocampus in non-mentally retarded autistic adolescents and adults. Neurology 53: 2145-2150.

Bartzokis G, Mintz J, Marx P, Osborn D, Gutkind D, Chiang F et al (1993). Reliability of in vivo volume measures of hippocampus and other brain structures using MRI. Magn Reson Imaging 11: 993-1006.

Bernasconi N, Bernasconi A, Andermann F, Dubeau F, Feindel W, Reutens DC (1999). Entorhinal cortex in temporal lobe epilepsy: a quantitative MRI study. Neurology 52: 1870-1876.

Botteron KN, Raichle ME, Drevets WC, Heath AC, Todd RD (2002). Volumetric reduction in left subgenual prefrontal cortex in early onset depression. Biol Psychiatry 51: 342-344.

Bowley MP, Drevets WC, Ongur D, Price JL (2002). Low glial numbers in the amygdala in major depressive disorder. Biol Psychiatry 52: 404-412.

Bremner JD, Narayan M, Anderson ER, Staib LH, Miller HL, Charney DS (2000). Hippocampal volume reduction in major depression. Am J Psychiatry 157: 115-118.

Bremner JD, Vythilingam M, Vermetten E, Nazeer A, Adil J, Khan $S$ et al (2002). Reduced volume of orbitofrontal cortex in major depression. Biol Psychiatry 51: 273-279.

Coffey CE, Wilkinson WE, Weiner RD, Parashos IA, Djang WT, Webb MC et al (1993). Quantitative cerebral anatomy in depression. A controlled magnetic resonance imaging study. Arch Gen Psychiatry 50: 7-16.

Convit A, McHugh P, Wolf OT, de Leon MJ, Bobinski M, De Santi S et al (1999). MRI volume of the amygdala: a reliable method allowing separation from the hippocampal formation. Psychiatry Res 90: 113-123.

Damasio AR, Graff-Radford NR, Eslinger PJ, Damasio H, Kassell N (1985). Amnesia following basal forebrain lesions. Arch Neurol 42: $263-271$.

Drevets WC (1999). Prefrontal cortical-amygdalar metabolism in major depression. Ann NY Acad Sci 877: 614-637.

Drevets WC, Price JL, Simpson Jr JR, Todd RD, Reich T, Vannier $M$ et al (1997). Subgenual prefrontal cortex abnormalities in mood disorders. Nature 386: 824-827.

Fuster JM (1997). The Prefrontal Cortex: Anatomy, Physiology, and Neuropsychology of the Frontal Lobe, 3rd edn. Lippincott-Raven: Philadelphia.

Gray JA (1983). A theory of anxiety: the role of the limbic system. Encephale 9: 161B-166B.

Kegeles LS, Malone KM, Slifstein M, Ellis SP, Xanthopoulos E, Keilp JG et al (2003). Response of cortical metabolic deficits to serotonergic challenge in familial mood disorders. $A m \mathrm{~J}$ Psychiatry 160: 76-82.

Kendler KS (1998). Gender differences in the genetic epidemiology of major depression. J Gender Specific Med 1: 28-31.

Kendler KS, Thornton LM, Prescott CA (2001). Gender differences in the rates of exposure to stressful life events and sensitivity to their depressogenic effects. Am J Psychiatry 158: 587-593.

Kessler RC, Berglund P, Demler O, Jin R, Koretz D, Merikangas KR et al (2003). The epidemiology of major depressive disorder: results from the National Comorbidity Survey Replication (NCS-R). JAMA 289: 3095-3105.
Kessler RC, McGonagle KA, Zhao S, Nelson CB, Hughes M, Eshleman $S$ et al (1994). Lifetime and 12-month prevalence of DSM-III-R psychiatric disorders in the United States. Results from the National Comorbidity Survey. Arch Gen Psychiatry 51: 8-19.

Khan AA, Gardner CO, Prescott CA, Kendler KS (2002). Gender differences in the symptoms of major depression in opposite-sex dizygotic twin pairs. Am J Psychiatry 159: 1427-1429.

Kuehner C (2003). Gender differences in unipolar depression: an update of epidemiological findings and possible explanations. Acta Psychiatr Scand 108: 163-174.

Lai T, Payne ME, Byrum CE, Steffens DC, Krishnan KR (2000). Reduction of orbital frontal cortex volume in geriatric depression. Biol Psychiatry 48: 971-975.

Mayberg HS, Liotti M, Brannan SK, McGinnis S, Mahurin RK, Jerabek PA et al (1999). Reciprocal limbic-cortical function and negative mood: converging PET findings in depression and normal sadness. Am J Psychiatry 156: 675-682.

Mervaala E, Fohr J, Kononen M, Valkonen-Korhonen M, Vainio P, Partanen K et al (2000). Quantitative MRI of the hippocampus and amygdala in severe depression. Psychol Med 30: 117-125.

Morgan MA, Romanski LM, LeDoux JE (1993). Extinction of emotional learning: contribution of medial prefrontal cortex. Neurosci Lett 163: 109-113.

Nolen-Hoeksema S (1987). Sex differences in unipolar depression: evidence and theory. Psychol Bull 101: 259-282.

Ongur D, Drevets WC, Price JL (1998). Glial reduction in the subgenual prefrontal cortex in mood disorders. Proc Natl Acad Sci USA 95: 13290-13295.

Parsey RV, Oquendo MA, Simpson NR, Ogden RT, Van Heertum $\mathrm{R}$, Arango $\mathrm{V}$ et al (2002). Effects of sex, age, and aggressive traits in man on brain serotonin 5-HT1A receptor binding potential measured by PET using [C-11]WAY-100635. Brain Res 954: 173-182.

Penza KM, Heim C, Nemeroff CB (2003). Neurobiological effects of childhood abuse: implications for the pathophysiology of depression and anxiety. Arch Women Ment Health 6: 15-22.

Rajkowska G, Miguel-Hidalgo JJ, Wei J, Dilley G, Pittman SD, Meltzer HY et al (1999). Morphometric evidence for neuronal and glial prefrontal cell pathology in major depression. Biol Psychiatry 45: 1085-1098.

Sapolsky RM (2000). Glucocorticoids and hippocampal atrophy in neuropsychiatric disorders. Arch Gen Psychiatry 57: 925-935.

Sarter M, Markowitsch HJ (1985). The amygdala's role in human mnemonic processing. Cortex 21: 7-24.

Seifert W (1983). Neurobiology of the Hippocampus. Academic Press: London, New York.

Sheline YI, Gado MH, Price JL (1998). Amygdala core nuclei volumes are decreased in recurrent major depression. Neuroreport 9: 2023-2028.

Sheline YI, Sanghavi M, Mintun MA, Gado MH (1999). Depression duration but not age predicts hippocampal volume loss in medically healthy women with recurrent major depression. J Neurosci 19: 5034-5043.

Sheline YI, Wang PW, Gado MH, Csernansky JG, Vannier MW (1996). Hippocampal atrophy in recurrent major depression. Proc Natl Acad Sci USA 93: 3908-3913.

Sloan DM, Kornstein SG (2003). Gender differences in depression and response to antidepressant treatment. Psychiatr Clin N Am 26: 581-594.

Spitzer RL, Williams JB, Gibbon M, First MB (1992). The structured clinical interview for DSM-III-R (SCID). I: History, rationale, and description. Arch Gen Psychiatry 49: 624-629.

Steffens DC, Byrum CE, McQuoid DR, Greenberg DL, Payne ME, Blitchington TF et al (2000). Hippocampal volume in geriatric depression. Biol Psychiatry 48: 301-309. 
Vakili K, Pillay SS, Lafer B, Fava M, Renshaw PF, Bonello-Cintron CM et al (2000). Hippocampal volume in primary unipolar major depression: a magnetic resonance imaging study. Biol Psychiatry 47: 1087-1090.

Vyas A, Mitra R, Shankaranarayana Rao BS, Chattarji S (2002). Chronic stress induces contrasting patterns of dendritic remodeling in hippocampal and amygdaloid neurons. J Neurosci 22: 6810-6818.
Vythilingam M, Heim C, Newport J, Miller AH, Anderson E, Bronen $\mathrm{R}$ et al (2002). Childhood trauma associated with smaller hippocampal volume in women with major depression. Am J Psychiatry 159: 2072-2080.

Zola-Morgan SM, Squire LR (1990). The primate hippocampal formation: evidence for a time-limited role in memory storage. Science 250: 288-290. 